\title{
Acute Cholecystitis as a Complication after Colonoscopy: A Case Report and Literature Review
}

\author{
Madalina-Maria Gorgan, loana Grigorescu, Dan L. Dumitrascu \\ $2^{\text {nd }}$ Medical Department, Iuliu Hatieganu University of Medicine and Pharmacy, Cluj-Napoca, Romania
}

Received: 28/07/2016

Accepted: $25 / 08 / 2016$

Published: $12 / 09 / 2016$

How to cite this article: Gorgan MM, Grigorescu I, Dumitrascu DL. Acute cholecystitis as a complication after colonoscopy: a case report and literature review. EJCRIM 2016;3:doi:10.12890/2016_000472.

Conflicts of Interests: The Authors declare that there are no competing interests.

This article is licensed under a Commons Attribution Non-Commercial 4.0 License

\section{ABSTRACT}

Acute cholecystitis after colonoscopy is a rare event, with less than 10 cases described in the literature. We report the case of a male patient with silent gallstones who underwent colonoscopy for follow-up of his Crohn's disease. The colonoscopy revealed erosions in the terminal ileum, from which biopsies were taken. A sessile polyp $4 \mathrm{~mm}$ in diameter at the recto-sigmoid junction was also removed. Less than $24 \mathrm{~h}$ after the colonoscopy, the patient complained of upper right quadrant pain, nausea and vomiting. Based on the clinical findings, laboratory data and ultrasonography, we diagnosed acute cholecystitis and excluded any complication after the colonoscopy. Laparoscopic cholecystectomy was performed and the patient was discharged.

\section{LEARNING POINTS}

- Cholecystitis following colonoscopy can be a rare complication or a coincidence.

- Rarely, manoeuvres during colonoscopy may dislodge small gallstones which then obstruct the bile duct causing acute cholecystitis.

- Imaging and the clinical picture help to differentiate bowel perforation, a fairly common early event after colonoscopy, from other complications.

\section{KEYWORDS}

Acute cholecystitis; colonoscopy; complication; gallstones.

\section{INTRODUCTION}

Colonoscopy is a routine procedure for investigating a wide range of gastrointestinal conditions and symptoms. Although complications after colonoscopy are rare, patients should be clinically followed for at least 24-48 h. Up to 3.3\% of patients report minor gastrointestinal symptoms, but severe complications are uncommon. The most frequent problems after colonoscopy are abdominal pain or discomfort and intestinal perforation or lower digestive tract bleeding. Complications such as haematoma or splenic rupture, acute appendicitis, mesenteric vessel damage and even acute cholecystitis are very rare but can occur after the procedure ${ }^{[1,2]}$. Acute cholecystitis following colonoscopy is a rare complication, with one of the first cases reported by Milman and Goldenberg ${ }^{[3]}$, but was also encountered in one of our patients who underwent a colonoscopy to evaluate existing intestinal pathology. 


\section{CASE PRESENTATION}

A 57-year-old male patient, with known Crohn's disease since 2012 and with significant cardiac pathology (hypertension, painful ischaemic heart disease and angina pectoris) was admitted to hospital complaining of mild diffuse abdominal pain associated with bowel movement disorders with diarrhoea that appeared only with increased consumption of dietary fibre. The patient had been treated previously for 1 year with budesonide ( $9 \mathrm{mg}$ per day) but had been able to cease treatment after remission of symptoms. During the current hospitalization, taking into account the clinical picture and the associated inflammatory bowel disease, it was decided that a colonoscopy was required.

Routine evaluation before the colonoscopy included laboratory tests, faecal calprotectin and abdominal ultrasound. Laboratory analysis showed essential hypercholesterolaemia (total cholesterol: $259 \mathrm{mg} / \mathrm{dl}$ ), without other pathological changes. C-reactive protein was within normal limits and faecal calprotectin was $112 \mathrm{mg} / \mathrm{kg}$, results that showed that there was minimal gastrointestinal inflammation. Ultrasound revealed fatty liver and multiple gallstones and sludge, which were asymptomatic.

A colonoscopy was performed the day after admission and revealed small erosions in the terminal ileum, from which biopsies were taken. A sessile polyp $4 \mathrm{~mm}$ in diameter was removed from the recto-sigmoid junction $40 \mathrm{~cm}$ from the anus. Within $12 \mathrm{~h}$ of colonoscopy, the patient experienced diffuse abdominal pain, which gradually increased in intensity and was subsequently concentrated in the upper right abdominal quadrant and was associated with nausea and food and bilious vomiting. Palpation revealed a distended abdomen and intense tenderness in the right upper quadrant; bowel movements were present.

Considering the symptoms and the gallstones seen on ultrasound, we suspected biliary colic and acute cholecystitis, but did not rule out bowel perforation, a common complication of colonoscopy. Laboratory tests showed leucocytosis (WBC: 16,290/ul) and normal liver enzymes. Plain abdominal radiography to exclude possible bowel perforation established there was no air or liquid in the peritoneal cavity. Ultrasonography showed gallbladder hydrops (Fig. 1), without dilation of the common bile duct, establishing the diagnosis of acute cholecystitis.

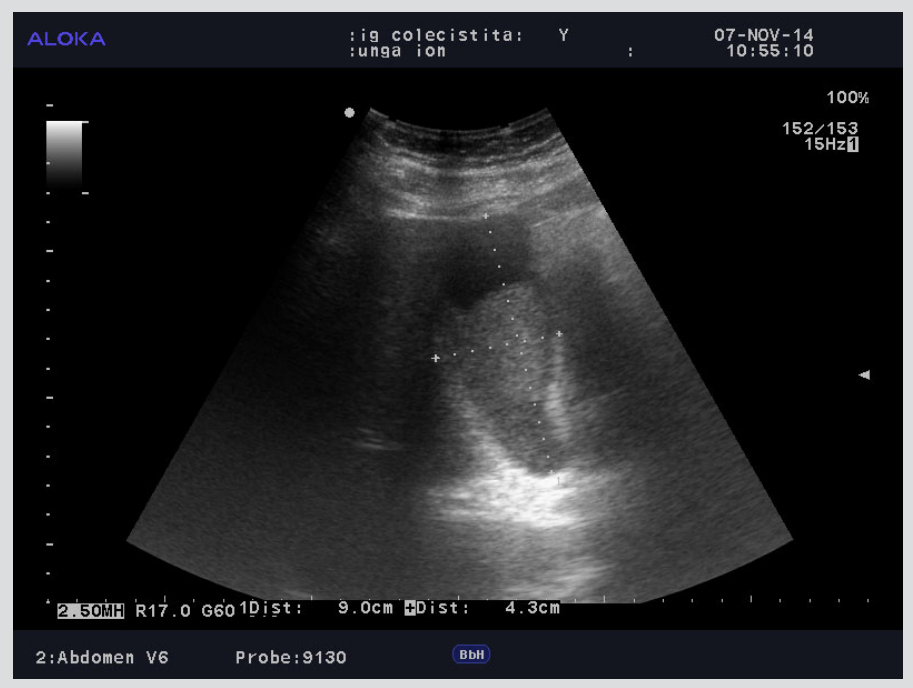

Figure 1. Ultrasound imaging findings: gallbladder hydrops and thickened gallbladder walls.

It was decided to postpone surgical management and initiate conservative treatment first. Oral nutrition was suppressed and treatment with antibiotics, analgesics and antispasmodic drugs was started. The painful symptoms completely resolved, but the patient continued to present nausea and vomiting and was re-evaluated 2 days after the onset of symptoms. Laboratory tests again showed leucocytosis (WBC: 16,160/ul) and mildly increased serum transaminases (GOT: $40 \mathrm{U} / \mathrm{l}$, normal value >37; GPT: $61 \mathrm{U} / \mathrm{l}$, normal value >40), without the presence of cholestasis. The patient was referred to surgery as a second ultrasound also showed thickened gallbladder walls and pericholecystic fluid. Laparoscopic cholecystectomy was performed 5 days after the onset of symptoms. The surgical diagnosis was gangrenous cholecystitis with subhepatic adherents block (in the omentum, liver and transverse colon). Histopathological findings of polymorphonuclear cells and small vessel thrombosis confirmed the surgical diagnosis (Figs. 2 and 3). After surgery, therapy with antibiotics, analgesics and anticoagulant prophylaxis was started. The patient slowly recovered. Although on the third day after cholecystectomy some bile (approximately 100 ml) was seen, the patient was discharged only 14 days after surgical intervention and 23 days after hospital admission. 


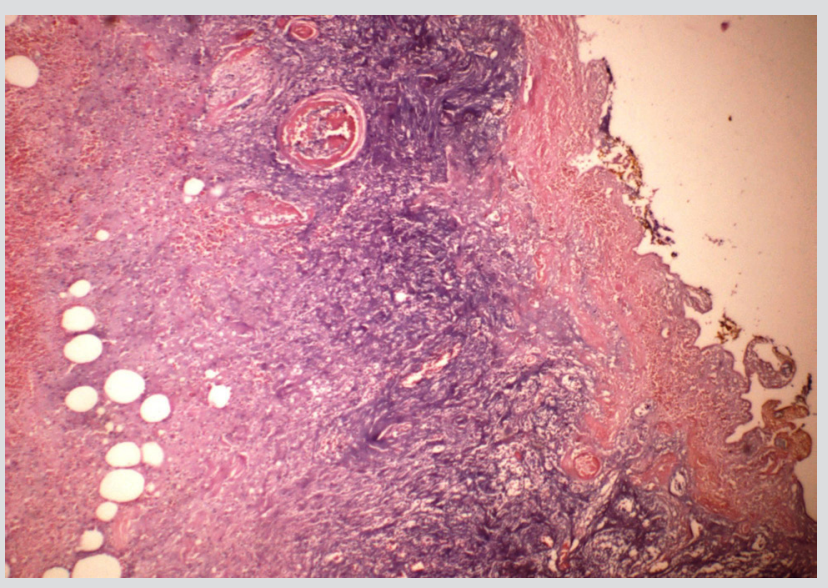

Figure 2. Small vessel thrombosis and epithelial erosions

(haematoxylin and eosin staining)

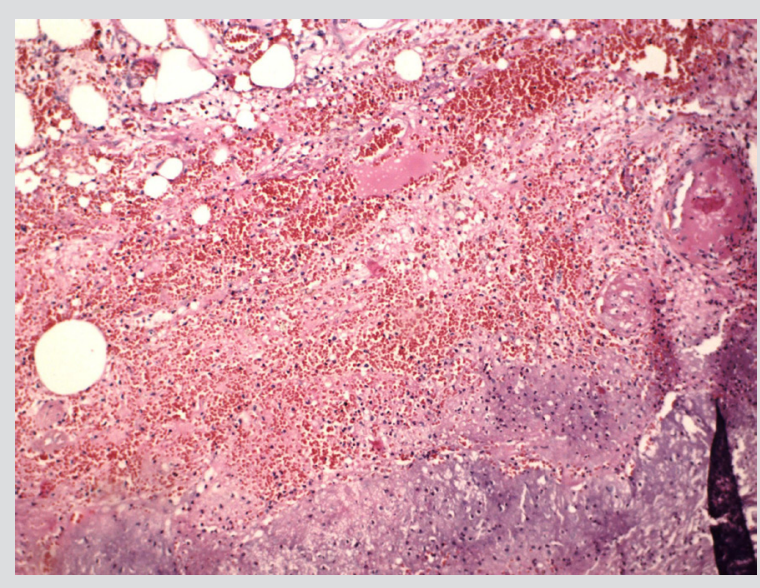

Figure 3. Mucosal polymorphonuclear cells (haematoxylin and eosin staining)

\section{DISCUSSION}

Complications after colonoscopy are rare, but should be kept in mind. The most common complication is intestinal perforation, with a reported rate of $0.3 \%{ }^{[4]}$, with haemorrhage the second most common. Other problems include rupture or splenic haematoma, acute appendicitis, acute cholecystitis and mesenteric vessel injury ${ }^{[3-5]}$.

Less than 10 cases of acute cholecystitis as a possible complication of colonoscopy have been described in the literature, including one case where the intraoperative diagnosis was of torsion of the gallbladder. All patients who experienced acute cholecystitis did so within $48-72 \mathrm{~h}$ of colonoscopy and had known gallstones. The cases described in the literature are presented in Table $1^{[4]}$.

\begin{tabular}{|l|l|l|l|}
\hline Author & Age/Sex & Colonoscopy Procedure & Time Until Symptoms (h) \\
\hline Milman and Goldenberg ${ }^{[6]}$ & $58 / \mathrm{F}$ & Polypectomy (cold biopsy) & 8 \\
\hline Milman and Goldenberg ${ }^{[6]}$ & $49 / \mathrm{F}$ & Random biopsy & 24 \\
\hline Aziz et al. ${ }^{[7]}$ & $63 / \mathrm{F}$ & Polypectomy & 72 \\
\hline Aziz et al. ${ }^{[7]}$ & $60 / \mathrm{M}$ & Polypectomy & 48 \\
\hline Fernandez-Martinez et al. ${ }^{\left[{ }^{[3]}\right.}$ & $76 / \mathrm{M}$ & Polypectomy (cold biopsy) & 48 \\
\hline Maddur et al. ${ }^{\left[{ }^{[3]}\right.}$ & $70 / \mathrm{M}$ & Polypectomy (cold snare and forceps) & 72 \\
\hline Maddur et al. ${ }^{[3]}$ & $70 / \mathrm{M}$ & $\begin{array}{l}\text { Polypectomy (cold snare and snare } \\
\text { electrocautery) }\end{array}$ & 48 \\
\hline Maddur et al. ${ }^{\left[{ }^{[3]}\right.}$ & Polypectomy (snare electrocautery) & 48 \\
\hline Warfe et al. ${ }^{[9]}$ & 57/F & None & 3 \\
\hline
\end{tabular}

Table 1. Cases of acute cholecystitis after colonoscopy

Acute cholecystitis is caused by bile duct obstruction by a gallstone leading to bile stasis within the gallbladder, causing inflammation of the gallbladder mucosa and infection ${ }^{[10]}$. The mechanism by which acute cholecystitis occurs after a colonoscopy is not known, but there are several theories. One assumes that the dehydration which occurs after bowel preparation produces bile stasis, bile lithogenicity and gallbladder distension which may cause a local inflammatory reaction. With pre-existing cholelithiasis, this can cause stone impaction in the gallbladder neck ${ }^{[3]}$. Another mechanism could be bacterial translocation from the colon to the gallbladder. 
Mechanical factors may also play a part ${ }^{[3,4]}$. We empirically consider that moving from one side to another during colonoscopy could lead to the mobilization of small gallstones which then block the bile duct. However, the association between colonoscopy and cholecystitis could be also a coincidence.

In our case, colonoscopy was carried out after the patient had consumed 4 litres of polyethylene glycol to prepare the colon. The procedure was performed without incident, and biopsies were taken from the terminal ileum. However, the patient presented with symptoms and signs of acute cholecystitis $12 \mathrm{~h}$ later. The diagnosis was confirmed by laboratory tests and ultrasonography. Although the exact cause of this rare complication is not known, our patient's case evolved as described in the literature ${ }^{[4]}$.

\section{REFERENCES}

1. Eisen GM, Gralnek JM, Canto MJ, Das A, Deviere J, Enns R, et al. Complications of colonoscopy. Gastrointest Endosc 2011:74:745-752

2. Ko CW, Dominitz JA. Complications of colonoscopy: magnitude and management. Gastrointest Endosc Clin N Am 2010;20:659-671.

3. Maddur H, Agrawal S, Fayard N, Chalasani N, Kahi C. Acute cholecystitis after colonoscopy: a case series. Gastrointest Endosc 2011;74:211-213.

4. Park TI, Lee SY, Lee JH, Kim MC, Kim BG, Cha DH. Acute cholecystitis after a colonoscopy. Ann Coloproctol 2013;29:213-215.

5. Yun JH, Jeong WJ, Chang WS, Jo MH, Park JK, Lee SJ, et al. A case of acute cholecystitis after colonoscopy. Korean J Gastroenterol 2013;61:42-45.

6. Milman PJ, Goldenberg SP. Colonoscopy cholecystitis. Am J Gastroenterol 2001;96:1666.

7. Aziz F, Milman P, McNelis J. Abdominal pain after colonoscopy: can it be acute cholecystitis? Dig Dis Sci 2007;52:2660-2661.

8. Fernandez-Martinez C, Pla-Marti V, Flors-Alandi C, Roig-Vila JV. Gangrenous cholecystitis after colonoscopy. Am J Gastroenterol $2002 ; 97: 1572$.

9. Warfe SR, Dobson H, Hong MKH, Ranasinghe WKB, Thomas PR, Cichowitz AG. Torsion of wandering gallbladder following colonoscopy. Case Reports Med 2013:808751.

10. Browning JD, Sreenarasimhaiah J. Gallstone disease. In: Feldman M, Friedman LS, Brandt LJ, editors. Sleisenger and Fordtran's gastrointestinal and liver disease pathophysiology diagnosis/management, 8th ed. Philadelphia, PA: Saunders Elsevier; 2006, pp. 1406-1410. 